\title{
Predicting Perception of Risks and Benefits within Novel Domains
}

\author{
Lenka Kostovičová, Jana Bašnáková, Viera Bačová \\ Institute of Experimental Psychology \\ Center of Social and Psychological Sciences, Slovak Academy of Sciences
}

\begin{abstract}
According to the cultural theory of risk, people's cultural worldviews can bias the evaluation of risks and benefits, even after reading balanced arguments on a given topic. This assumption was tested on two controversial domains, which were relatively novel for the chosen population: nanoscience and HPV vaccination. Participants $(N=339)$ evaluated respective risks and benefits, either without or after reading balanced arguments. Contrary to earlier findings, positive perception of nanoscience was associated with egalitarianism. Worldviews of the pro- and conadvocate of nanoscience influenced risk perception among people with little prior knowledge. Assessment of risks inherent to HPV vaccination was positively associated with hierarchism among men, negatively with familiarity among women, and sensitive to the worldviews of the advocates. We provide a discussion on how evaluation of risks and benefits in novel domains is affected by a complex interplay of cultural cognition, domain familiarity, personal relevance and general risk attitudes.
\end{abstract}

Key words: risk perception, novel domains, cultural worldview, source credibility, familiarity, personal relevance

\section{Introduction}

Risk perception is inevitably biased. For instance, the relationship between benefits and risks is likely to be inversed in the human mind, even though they are usually positively correlated in real-life environment. People tend to believe that beneficial activities and objects in-

Acknowledgements: This research was supported by VEGA grant No. 2/0154/13 - 'Social influences in individual decision making' and VEGA grant No. 2/ 0085/17 - 'Cognitive limits of effective information processing and communication' awarded by the Ministry of Education, Science, Research and Sports of the Slovak Republic and the Slovak Academy of Sciences.

Correspondence concerning this artice should be addressed to Lenka Kostovičová, Institute of Experimental Psychology, CSPS SASc., Dúbravská cesta 9, 841 04, Bratislava, Slovak Republic, E-mail: lenka.kostovicova@savba.sk

Received October 12, 2016 volve only low risks, and vice versa (Sunstein, 2002). Typical examples of this tendency are rather controversial topics, such as GMO, stem cell research, tuition payment, possession of handguns, euthanasia, abortions, vaccination or helping refugees. At the same time, such domains often represent major public health and policy issues since refusing child vaccination or engaging in xenophobic reactions are potentially dangerous tendencies.

Thus, analyzing how people assess risks and benefits in such public-interest domains has highly important practical implications. Indeed, behavioral (e.g., Brewer et al., 2007; Renner \& Reuter, 2012) and neuroscientific evidence (e.g., Chua et al., 2011; Falk, Berkman, Mann, Harrison, \& Lieberman, 2010) on how worried or threatened people feel, predicts real-life behavior with severe consequences for both individuals and society.

People often evaluate risks and benefits in complex domains, even though they lack the necessary competence, experience, information 
and time. They engage in heuristic reasoning, using mental shortcuts based on simple rules such as similarity of the cases or ease of example recall from memory (Tversky \& Kahneman, 1974). Employing these principles, they are able to make accurate judgments and decisions, but only in appropriate environments. However, heuristic reasoning can also lead to illusions and errors, especially when it crowds out more systematic thinking. Two of the many well-documented heuristic mechanisms of human reasoning are confirmation bias and credibility heuristic.

Confirmation bias is a tendency to favor, seek, interpret, remember and recall information in a way that corresponds to prior expectations, beliefs or hypotheses of the reasoner (Nickerson, 1998). This is a substantial cognitive difficulty, since open-minded critical thinkers should be capable of decoupling their existing views and attitudes from systematic evaluation of arguments and evidence (Stanovich, West, \& Toplak, 2013). Distorted information search, interpretation and recall due to confirmation bias have been suggested to explain several robust phenomena of human cognition, e.g. illusory correlation or belief persistence. Highly relevant consequences of this cognitive deviation range from biased evidenceevaluation of jurors to conservativism among scientists (Nickerson, 1998). Interestingly, susceptibility to confirmation bias is unrelated to intelligence (Stanovich et al., 2013).

The concept of credibility has been defined in numerous ways: trustworthiness and attractiveness of a source of influence, its prestige, or the history of its previous accuracy (Nesler, Aguinis, Quigley, \& Tedeschi, 1993). An important factor closely related to perceptions of trustworthiness, accuracy and validity, and judgments on credibility, is expertise (Hilligoss \& Rieh, 2008). People rely on credibility of the source, especially when they lack prior attitudes toward the issues and knowledge about the phenomena (Kumkale, Albarracín, \& Seignourel, 2010). Thus, a rule of thumb suggests: the more credible the source of an argument, the stronger the argument.

According to recent studies, the use of particular heuristic principles in processing information on risks and benefits is also closely related to people's cultural worldviews.

\section{The Cultural Cognition Thesis of Risk Perception}

According to the cultural theory of risk (Douglas \& Wildavsky, 1983), individuals form beliefs about risks and benefits in a way that reflects and reinforces their commitments to an idealized form of social order. According to their "group" and "grid" typology, people can be placed on a two-dimensional scale of individualism/communitarianism and hierarchism/egalitarianism, as depicted in Figure 1. A "high group" worldview (communitarianism) favors a solidaristic society, where the needs of the collective are superior to those of the individual and in which society is responsible for securing the conditions for individual growth and prospering. Conversely, a "low group" way of life (individualism) is characterized by a low level of collective control or interference, and a society in which citizens are expected to take care of the conditions of their own well-being. A "high grid" worldview (hierarchism) prefers hierarchical social order, with a stratified way of assigning resources, privileges, rights and obligations on the basis of stable personal characteristics, such as gender, class, ethnicity, and lineage. A "low grid" way of life (egalitarianism) is typical for societies, in which such individual attributes are irrelevant to the distribution of opportunities, prerogatives, wealth and status (Kahan, Braman, Cohen, Gastil, \& Slovic, 2010; Kahan, Braman, Slovic, Gastil, \& Cohen, 2009).

Since people are expected to perceive risks and benefits consistently with their own cul- 


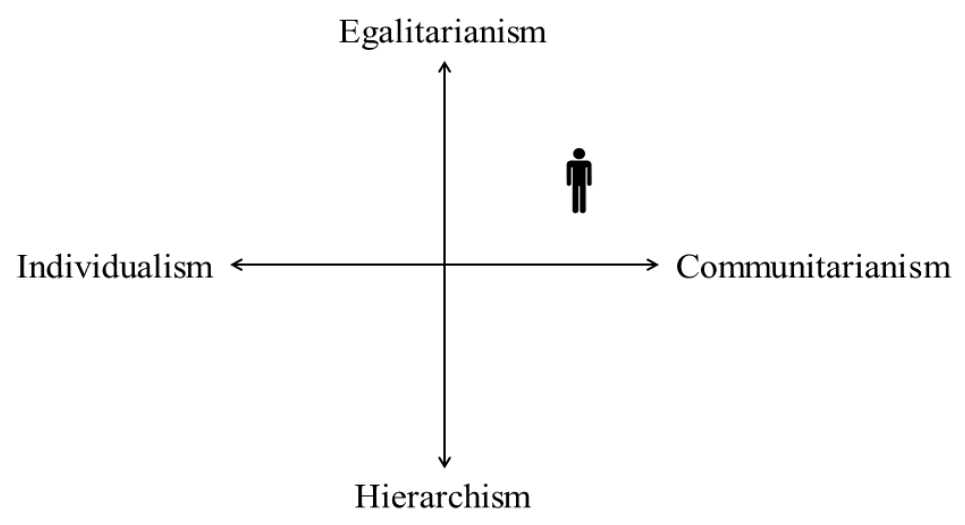

Note. Adapted from Kahan, 2012.

Figure 1 Dimensions of cultural worldview

tural evaluations of dangerous activities and policies for their regulation, the following assumptions were derived (Kahan et al., 2009, 2010). Individualists are against actions which might intrude on their individual choices, such as regulations based on mandatory behavior (e.g., child vaccination). They tend to react disapprovingly to claims of technological and environmental risks (e.g., nanotechnology), recognition of which threatens markets and commerce. Hierarchists also dismiss statements on these categories of potential risks. Thus, claims about negative aspects of such activities question the authority and credibility of social elites. They are also in opposition to anything that could jeopardize traditional norms, such as registered partnerships for same-sex couples. In contrast, people preferring egalitarianism encourage behavior that breaks conventions and traditional, patriarchal standards. Moreover, egalitarians and communitarians, in contrast, believe that industry and commerce - both associated with selfishness and inequity - represent danger for society and nature, and accept claims of corresponding risks. Finally, people of communitarian worldview support collective commitments and oppose unrestricted promotion of individual interests.

There is a considerable amount of empirical evidence for these patterns in studies on risk perception. Jenkins-Smith (2001) found that stigma associated with nuclear waste repositories was less prevalent among hierarchists and individualists. According to Leiserowitz (2005), people who perceive climate change as a low or non-existing danger are mostly holding hierarchical and individualistic worldview. These effects are not limited to the U.S. culture, where the theory originated, as recent studies from Europe suggested that individualists were much less likely to accept policies involving nudges (Sweden; Hagman, Andersson, Västfjäll, \& Tinghög, 2015), and that people's concerns about climate change, their willingness to adopt respective policies and to change one's own behavior were negatively predicted by hierarchism and individualism (Switzerland; Shi, Visschers, \& Siegrist, 2015). In addition, a meta-analysis where nonU.S. studies accounted for half of the sample, confirmed that individualistic and hierarchical values have a medium negative effect on cli- 
mate change belief (Hornsey, Harris, Bain, \& Fielding, 2016).

In a study by Kahan, Braman, Gastil, Slovic, and Mertz (2007), cultural values explained variance in risk perception better than a large number of other variables, including age, education, and political and religious affiliation. Hierarchists were those who perceived the highest risks associated with abortions; and the highest levels of gun ownership risks and environmental risks were perceived among egalitarians and communitarians. Moreover, their study showed that cultural worldview interacts with the impact of race and gender on risk perception in line with cultural identity of the participants. Combination of egalitarianism and communitarianism led to higher perceived risks of nanoscience (Kahan et al., 2009) and lower perceived risks of HPV vaccination (Kahan et al., 2010).

What are some of the proposed mechanisms mediating the effect of cultural worldview on evaluation of risks and benefits? Kahan et al. $(2009,2010)$ proposed and tested two of them, experimentally manipulating exposure to arguments as well as cultural worldviews of the sources of the arguments. First, in line with confirmation bias, the authors suggested that people will process provided arguments selectively and they will favor the information which reinforces their prior position. In other words, balanced arguments will not lead to more balanced risk perceptions. Instead, the gap between people who are inclined to credit claims of specific risks and those who are inclined to dismiss them will grow substantially after exposure to balanced pro- and con-arguments. Indeed, in the domain of nanotechnology (Kahan et al., 2009), argument exposure strengthened the positive association between risk perception and preference for egalitarian and communitarian cultural values. Conversely, in the domain of HPV vaccination (Kahan et al., 2010), argument exposure strengthened the positive association between risk perception and preference for hierarchical and individualistic cultural values.

Next, consistently with the credibility heuristic, Kahan et al. (2010) suggested that the extent of the argument exposure effect will vary depending on the source credibility based on perceived cultural worldviews. In other words, when a supposed author of the argument that a person endorses holds similar cultural worldviews to that person, her/his prior position toward the domain becomes more extreme; and vice-versa. Indeed, the more participants' worldviews resembled those of the con-advocate of vaccination and the more they differed from the worldviews of the pro-advocate, the more risks and less benefits of vaccination participants perceived after reading the arguments.

Besides verifying the cultural cognition thesis assumptions, the authors also tested the familiarity hypothesis of risk perception of nanotechnology. It posits that support for novel domains grows as awareness and knowledge of the domains expands. Indeed, prior self-reported familiarity with nanoscience was positively correlated with the view that nanotechnology's benefits outweigh its risks (Kahan et al., 2009). However, the authors' findings did not support the familiarity hypothesis because holding cultural worldviews constant, exposure to information did not affect risk perception. In studies on risk perception of vaccination against HPV, the role of prior familiarity has not been tested yet.

\section{The Present Experiment}

We aimed to replicate the studies by Kahan et al. $(2009,2010)$ on a sample from Slovakia, which has different historical, social, political and economic background than the original U.S. samples. Moreover, unlike in the U.S., the two domains - nanoscience and vaccination against HPV - have not yet been subjected to public 
debate in the local context, and the views were not yet clearly delineated according to ideological axes. Both domains - nanoscience and vaccination against HPV - concern potential severe individual and social consequences and are closely related to health risks. However, HPV vaccination of young girls is more personally relevant to women, and nanoscience is rather gender-neutral and associated not only with health risks but also with threats to the environment, national security and privacy (Kahan et al., 2009). Unlike the original study, we used the same group of people to examine how they assess risks and benefits of the two domains. It allowed us to look at the domain specificity of risk perception.

In the two-part experiment reported here, we adopted the methodology designed by Kahan et al. (2010) to test the proposed mechanisms of cultural cognition and to identify the factors that underlie perception of respective risks and benefits. Firstly, we were interested in whether the cultural dimensions and risk perception are related in the manner that has been repeatedly identified in the studies with the U.S. samples. Namely, whether communitarianism and egalitarianism are negatively associated with risk perception of nanoscience and positively associated with risk perception of HPV vaccination.

Subsequently, we tested the confirmation bias mechanism. We asked whether exposure to balanced arguments strengthens the relationships between cultural worldviews and risk perception. For instance, whether people who initially considered HPV vaccination as rather risky will perceive it as even riskier after they have read balanced pro- and con-arguments, and vice versa. Next, we tested the credibility heuristic mechanism. We wanted to know whether the strength of the arguments depends on the source credibility, operationalized as fit of cultural worldviews between the participant and the arguments' advocates. For instance, whether people who initially perceived nanotechnology as rather beneficial will consider it as even more beneficial after reading arguments of a pro-advocate who holds similar cultural worldviews to theirs, but not after reading arguments of a pro-advocate with different cultural worldviews. Finally, we were interested in the interplay between proposed mechanisms and domain familiarity.

\section{Method}

\section{Participants and Design}

Using personal and collective invitations via e-mails, electronic and printed calls, we recruited people of various ages and occupations to obtain a diversified sample. For this purpose, the calls for participation were also forwarded to discussion fora and social network websites that are visited by individuals of specific views and values (e.g., conservative "Alliance for Family" or individualistic "Young Entrepreneurs Association of Slovakia"). We recruited 481 persons, but data from only 339 were analyzed and are reported here (234 females and 105 males; age range $18-76$ years, $M=30.6$ years, $S D=10.2$ ). The remaining 142 persons were excluded prior to analysis because we suspected that they did not read the arguments in sufficient detail, if at all, as they did not reach a threshold of at least 30 seconds spent on each screen with arguments (defined in a separate pretest with $N=30$ ). Half of the final sample $(n=170)$ were undergraduates, one third $(n=$ 112) had a university degree and the rest had high-school education.

In the first part of our experiment, designed to study the confirmation bias mechanism, we randomly allocated 106 participants either to the control group without arguments $(n=60 ; 65.0 \%$ females) or to the first experimental group with anonymous balanced pro- and con-arguments ( $n=46 ; 67.4 \%$ females). In the second part of 
our experiment, designed to study the credibility heuristic mechanism, the remaining 233 participants $(70.4 \%$ females $)$ were assigned to the second experimental group with the same arguments as the first experimental group. But this time the arguments were supposedly written by two advocates with mutually different cultural worldviews (e.g., hierarchical individualist and egalitarian individualist). We ended up with twelve subgroups - all combinations of the four possible pro-advocates (A, B, C or D) and the four possible con-advocates (A, B, C or D), as specified in the Materials section. The design of our experiment is depicted in Figure 2.

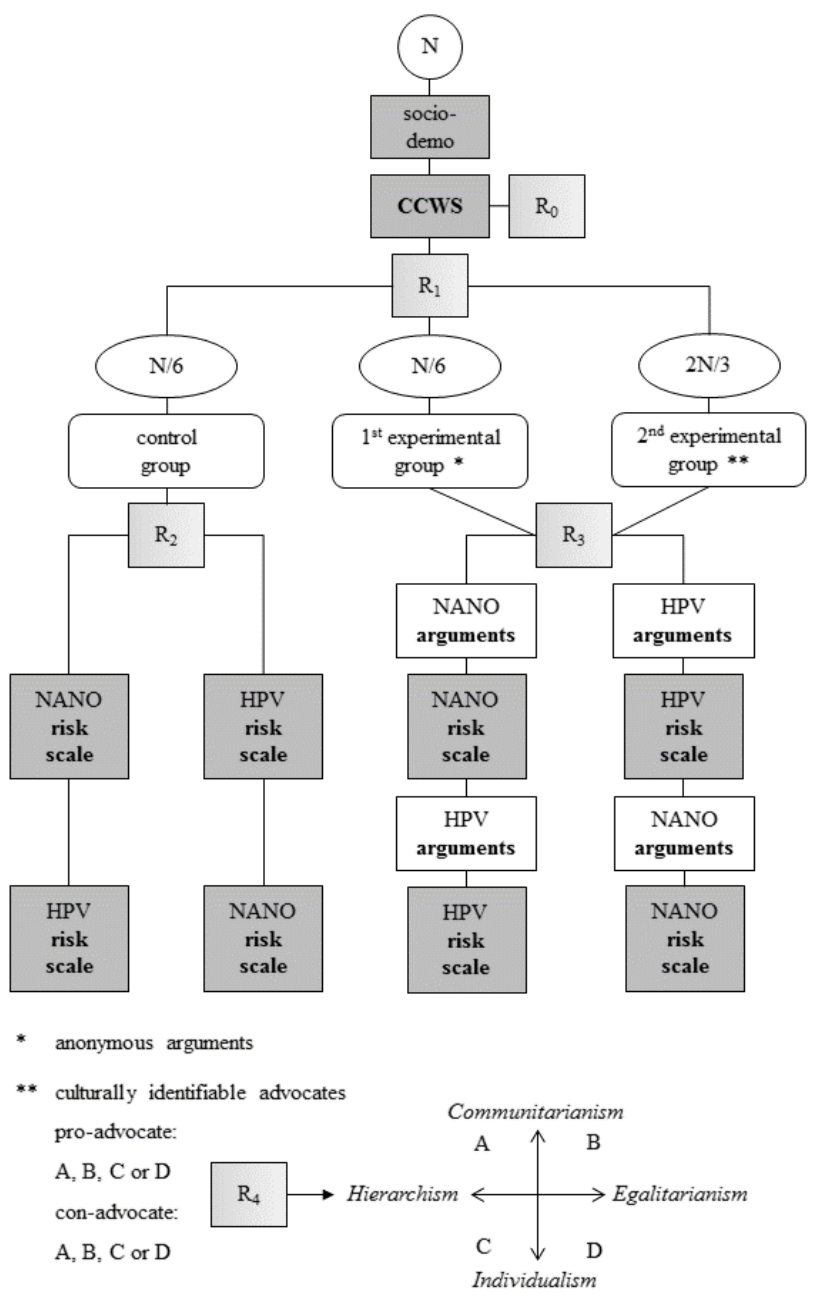

Note. "R" stands for randomization.

Figure 2 Flowchart of the experiment design 


\section{Materials and Procedure}

First, participants answered a few socio-demographic questions and proceeded with the Cultural Cognition Worldview Scale items.

\section{Cultural worldview}

All participants filled out the long version of the Cultural Cognition Worldview Scales (CCWS; Kahan, 2012). The questionnaire consists of a 13-item Hierarchy-Egalitarianism and a 17-item Individualism-Communitarianism scales. Participants indicated their attitude on 6-point Likert scale (1 - "strongly disagree"; 6 - "strongly agree"). After reversing part of the responses, two scores were calculated for each participant - the degree of egalitarianism (13 for absolute hierarchism; 78 for absolute egalitarianism) and communitarianism ( 17 for absolute individualism; 102 for absolute communitarianism). Both scales had sufficient internal consistency, egalitarianism: $\alpha=.74$, communitarianism: $\alpha=$.79. Translation of the questionnaire was carried out in several phases, including cognitive interviews and consultations with experts from different fields concerning terminology, such as social psychology, cross-cultural psychology and political science. We provide the Slovak translation of the scales in the Appendix and two examples of each di- mension in Table 1 (Kahan, 2012; "R" for reversed). For the sake of methodological rigor, we treated the cultural dimensions as continuous, not categorical variables.

\section{Arguments}

All our participants received short initial descriptive information on nanoscience and HPV vaccination. The order of the two domains was counterbalanced. The control group did not read any arguments before responding to riskbenefit items. The two experimental groups were administered pro- and con-arguments in two paragraphs, juxtaposed and rotated in position. The quantitative and qualitative aspects of the arguments were balanced, including the length of the text, number of arguments mentioned, frequency and format of numerical data, presence of expressive words or percentage of emotionally arousing words. We present short passages from the pro- and con-arguments on vaccination (adapted from Kahan et al., 2010) and nanoscience (adapted from Kahan et al., 2009) in Table 2.

\section{Advocates}

In the second experimental condition, the arguments were ascribed to two of the four advocates $(\mathrm{A}, \mathrm{B}, \mathrm{C}$ or $\mathrm{D})$, representing the extreme positions matching the four quadrants, e.g.

Table 1 Four items from the Cultural cognition worldview scales

\begin{tabular}{ll}
\hline & \multicolumn{1}{c}{ Examples of the CCWS items } \\
\hline $\begin{array}{l}\text { Hierarchism - } \\
\text { Egalitarianism }\end{array}$ & $\begin{array}{l}\text { We have gone too far in pushing equal rights in this country (R). } \\
\text { Our society would be better off if the distribution of wealth was } \\
\text { more equal. }\end{array}$ \\
\hline $\begin{array}{l}\text { Individualism - } \\
\text { Communitarianism }\end{array}$ & $\begin{array}{l}\text { Private profit is the main motive for hard work (R). } \\
\text { It is society's responsibility to make sure everyone's basic needs } \\
\text { are met. }\end{array}$ \\
\hline
\end{tabular}


Table 2 Passages from the arguments for and against HPV vaccination and nanotechnology

\begin{tabular}{|c|c|}
\hline & Pro(+) and con(-) arguments \\
\hline \multirow{2}{*}{ HPV vaccination } & $\begin{array}{c}{[+] \ldots \text { The vaccine against HPV has been approved by the European }} \\
\text { Medicines Evaluation Agency (EMEA) ... }\end{array}$ \\
\hline & $\begin{array}{l}{[-] \text {... However, vaccinated girls may assume that the vaccine }} \\
\text { provides them with complete protection ... }\end{array}$ \\
\hline \multirow{2}{*}{ Nanoscience } & $\begin{array}{l}{[+] \text {... Nanotechnologies also have a potential to provide new and }} \\
\text { better treatments for diseases ... }\end{array}$ \\
\hline & $\begin{array}{c}{[-] \text {... There are justified concerns that certain useful properties of }} \\
\text { nanomaterials may also be dangerous ... }\end{array}$ \\
\hline
\end{tabular}

Table 3 Examples of the publication titles of the four advocates

\begin{tabular}{ll}
\hline & \multicolumn{1}{c}{ Publications of the advocates } \\
\hline $\begin{array}{l}\text { Egalitarian } \\
\text { Communitarianist }\end{array}$ & $\begin{array}{l}\text { How to raise children: struggling with stereotypes about men and } \\
\text { women } \\
\text { Selfishness of individualism: divided we fall }\end{array}$ \\
\hline $\begin{array}{l}\text { Egalitarian } \\
\text { Individualist }\end{array}$ & $\begin{array}{l}\text { For equal rights and responsibilities, regardless of gender, age or } \\
\text { origin } \\
\text { We are not small kids: the government cannot make decisions for us }\end{array}$ \\
\hline $\begin{array}{l}\text { Hierarchical } \\
\text { Communitarianist }\end{array}$ & $\begin{array}{l}\text { Not discrimination against minorities, but against majority, is the } \\
\text { problem } \\
\text { Towards progressive taxation: the richer pay more }\end{array}$ \\
\hline $\begin{array}{l}\text { Hierarchical } \\
\text { Individualist }\end{array}$ & Where feminists are wrong: society needs strong men \\
\hline
\end{tabular}

egalitarian individualist. We did not use photographs of the advocates as the original authors did in their study (Kahan et al., 2010), as we suspected that this would introduce additional uncontrollable factors into the design, such as personal sympathy. We only provided our participants with three titles of the supposed publications of the pro- and con-advocates. Given the within-subject factor of domain (HPV vaccination and nanotechnology), we used $2 \times 3$ titles for each of the four advocates. We present some examples in Table 3.
The arguments were randomly matched with the advocates. Each advocate (A, B, C, D) could be allocated to any paragraph and, at the same time, be opposed to any one of the other advocates. Hence, there were 12 possible pairings in total $[\mathrm{AB}, \mathrm{AC} \ldots, \mathrm{DC}]$. Members of the second experimental group were randomly assigned to one of these advocate pairs.

We adopted the term "cultural affinity" (Kahan et al., 2010), i.e. the relative proximity of the cultural values of the participant to the perceived values of the con-advocate. The rela- 
tive distance of each participant's cultural worldview from the worldview of the two advocates was calculated as the difference in Euclidean distances between points. The higher cultural affinity of participants, the more similar are their cultural values to those of the conadvocate and the more different are their cultural values from those of the con-advocate. An example is depicted in Figure 3.

\section{Risk-benefit scales}

In this part of the experiment, participants in all three conditions first indicated how familiar they were with the two domains (the "familiarity" questions: "How much did you know about nanotechnology [HPV vaccination] until today?" (1 - "nothing at all"; 6 - "a lot"). Subsequently, participants responded on 6-point Likert scale (either 1 - "strongly disagree"; 6 "strongly agree" or 1 - "not at all beneficial"; 6 - "absolutely beneficial") to a set of items associated with risks and benefits of nanotechnology and HPV vaccination. After a preliminary analysis, we shortened the original 6-item risk scales (based on Kahan et al., 2009, 2010) to 4-item versions, in order to render the scales more uniform and to avoid ambiguity associated with the two excluded items. Both scales showed sufficient internal consistency, Risk_Nano: $\alpha=.72$, Risk_Vacc: $\alpha=.79$. All 12 items are listed in Table 4 (" $\mathrm{R}$ " for reversed).

\section{Results}

Overall, risk perception of nanotechnology was negatively correlated with egalitarianism $(r=-.15, p=.008)$ and familiarity $(r=-.20, p<$ $.001)$. In a similar manner, risk perception of HPV vaccination was negatively associated with egalitarianism $(r=-.21, p<.001)$ and familiarity $(r=-.11, p=.045)$. Participants who rated themselves as highly familiar with the domain and whose cultural values were less hierarchical

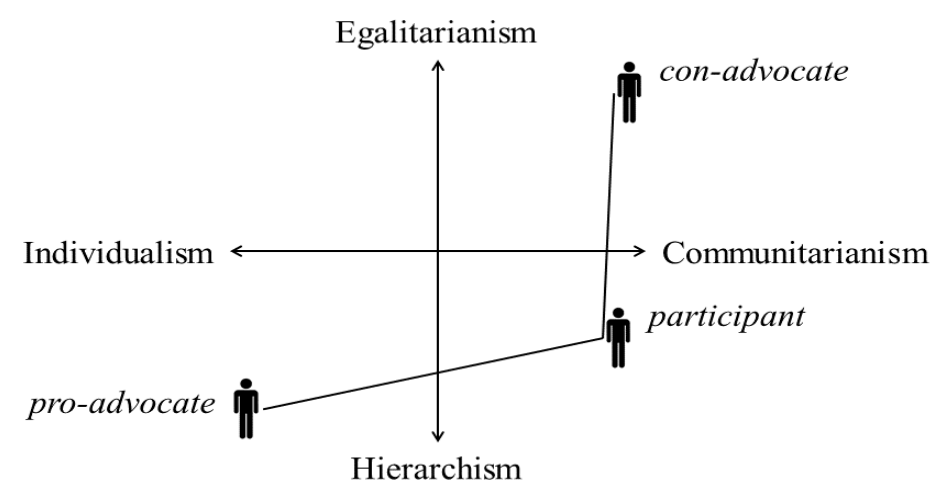

Note. Cultural affinity, relative distance from the two advocates, was calculated as PCA - PPA, i.e. participant's $(\mathrm{P})$ distance from the con-advocate $(\mathrm{CA})$ minus participant's $(\mathrm{P})$ distance from the pro-advocate $(\mathrm{PA})$.

Figure 3 One possible combination of positions of the advocates and their distance from the participant 
Table 4 Items of the two risk-benefit scales

\begin{tabular}{ll}
\hline \multicolumn{1}{c}{ Risk-benefit scales } \\
\hline The HPV vaccine is safe for use among young girls (R). \\
Universal vaccination of girls for HPV could endanger their health. \\
Girls vaccinated against HPV could be more likely to practice \\
unprotected sex. \\
How beneficial would you say universal vaccination of girls against \\
HPV is likely to be (R)? \\
Deleted: Universal vaccination of girls for HPV will lead girls to \\
become more sexually active. \\
Deleted: It is important to devise public health policies to reduce the \\
spread of HPV. \\
Nanotechnology products are generally safe for use (R). \\
Nanomaterials could be harmful to people and the environment. \\
Nanotechnology-based devices could pose a threat to national \\
security and privacy. \\
How beneficial for mankind would you say use of nanotechnologies \\
is likely to be (R)? \\
Deleted: We still do not know all the properties of nanomaterials \\
and respective risks. \\
Deleted: It is important to devise public health and safety policies to \\
control the usage of nanotechnologies.
\end{tabular}

tended to see greatest benefits and smaller risks in both nanotechnology and HPV vaccination. In addition, the two cultural dimensions $(r=$ $.21, p<.001)$ as well as risk measures were positively correlated $(r=.38, p<.001)$ and there was a positive relation between egalitarianism and familiarity with HPV vaccination $(r=.14, p=$ $.009)$.

\section{Risk Perception of Nanoscience}

In the control group $(n=60)$, participants familiar with nanoscience $(n=25, M d n=10.0$, $I Q R=4.0)$ considered it less risky than those with low prior knowledge $(n=35, M d n=12.0$, $I Q R=3.0), M-W U=284.0, p=.020, r_{m}=.30$. Given the lack of theoretical reasons for apply- ing the three-step regressions as implemented in the original studies, we conducted a series of stepwise regressions with backward method and the following predictors: egalitarianism, communitarianism, cultural affinity (only in the second experimental group), argument exposure, familiarity, gender, age, and respective interactions (each two-way interaction plus threeway interaction of worldviews and arguments). Prior to all regression analyses, we tested the data for normality and homoscedasticity, and checked the collinearity problems via the variance inflation factors. We also conducted the Mahalanobis distance, Cook's distance and Durbin-Watson tests to check the assumptions in regard to outliers, influential cases and autocorrelation in the residuals (Field, 2009). We 
excluded four outliers from the two separate analyses of the second experimental group.

We found that the effect of exposure to arguments did not interact with cultural values. According to the model with best fit $(n=106), R^{2}=$ $.18, F=7.39, p<.001$, significant positive predictors of risk perception were hierarchism $(\beta=$ $0.29, t=3.12, p=.002)$, non-familiarity $(\beta=0.28$, $t=3.03, p=.003)$ and exposure to arguments $(\beta=0.20, t=2.09, p=.039)$. Furthermore, risk perception was positively correlated with cultural affinity $(r=.14, p=.036)$.

Based on these preliminary analyses, we conducted simple moderation analyses using the SPSS macro PROCESS (Hayes, 2013). We found that the effect of cultural affinity on risk perception was moderated by familiarity. Relative proximity of cultural values to those of the conadvocate was positively related to risk perception only among people with low prior knowledge of nanoscience (Figure $4 ; n=231$ ).

\section{Risk Perception of HPV Vaccination}

In the control group, participants familiar with HPV vaccination $(n=28, M d n=11.0, I Q R=$ $5.5)$ considered it less risky than those with low prior knowledge $(n=32, M d n=13.0, I Q R=5.5)$, $M-W U=281.5, p=.013, r_{m}=.32$. Based on results of stepwise regression with backward method, neither the effect of exposure to arguments nor its interaction with cultural values predicted risk perception. According to the model with best fit $(n=106), R^{2}=.13, F=3.86, p=.006$, positive predictors of risk perception were non-familiarity $(\beta=0.29, t=2.61, p=.010)$, interaction of gender and hierarchism $(\beta=0.29, t=2.51, p=.014)$, interaction of gender and non-familiarity $(\beta=0.19$, $t=1.82, p=.072)$ andhierarchism $(\beta=0.16, t=1.67$, $p=.098)$. The model was significant, $F=4.89$, $p<.001$, and explained approximately $13 \%$ of the variance in risk perception.

\section{CONCEPTUAL DIAGRAM}

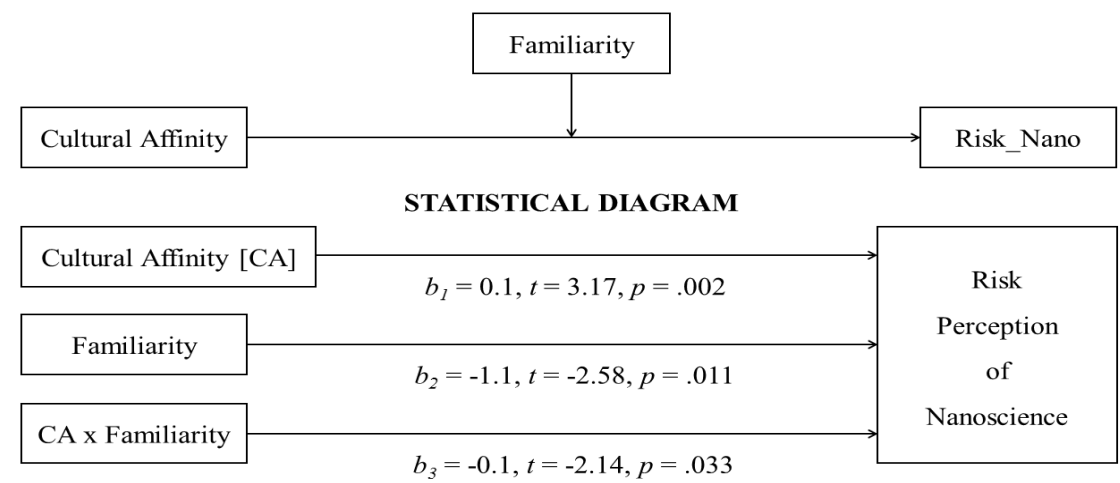

\begin{tabular}{lcccc}
\multicolumn{4}{l}{ Conditional effects: } \\
\hline Familiarity & effect & $\boldsymbol{t}$ & $\boldsymbol{p}$ & $\mathbf{9 5 \%} \boldsymbol{C I}$ \\
\hline Low & 0.04 & 3.17 & .002 & {$[0.02,0.07]$} \\
High & $<0.01$ & -0.20 & .844 & {$[-0.03,0.03]$} \\
\hline
\end{tabular}

Figure 4 Familiarity as a moderator of the effect of cultural affinity on risk perception of nanoscience 
Stepwise regression with backward method of the responses in the second experimental group ( $n=231)$ with pro- and con-advocates showed that not only egalitarianism $(\beta=-0.51$, $t=-4.30, p<.001)$, gender $(\beta=-1.01, t=-2.86$, $p=.005)$, and their interaction $(\beta=1.16, t=3.00$, $p=.003)$, but also relative proximity to con-advocate $(\beta=0.14, t=2.17, p=.031)$ predicted risk perception. The model was significant, $F=6.76$, $p<.001$, and explained approximately $9 \%$ of the variance in risk perception.

Simple moderation analyses showed that gender moderates the effects of hierarchism and familiarity on risk perception. Overall, hierarchism was positively related to risk perception only amongmen(Figure 5; $n=339$ ) and familiaritywas negatively associated with risk perception only amongwomen (Figure 6; $n=339$ ).

\section{Discussion}

The two-part experiment reported here tested the mechanism by which cultural cognition might affect perception of risks and benefits confirmation bias and credibility heuristic, and moderators of these effects. Our research is original for two reasons: first of all, our sample is culturally different from the original studies, which were conducted on the U.S. population, and is also much less familiar with the domains in question. In particular, there was no or only limited public discussion, and this gives us a reason to assume that discourse about the domains is not yet neatly "packaged" along ideological lines. In contrast to previous studies, we also employed a within subject factor that

\section{CONCEPTUAL DIAGRAM}

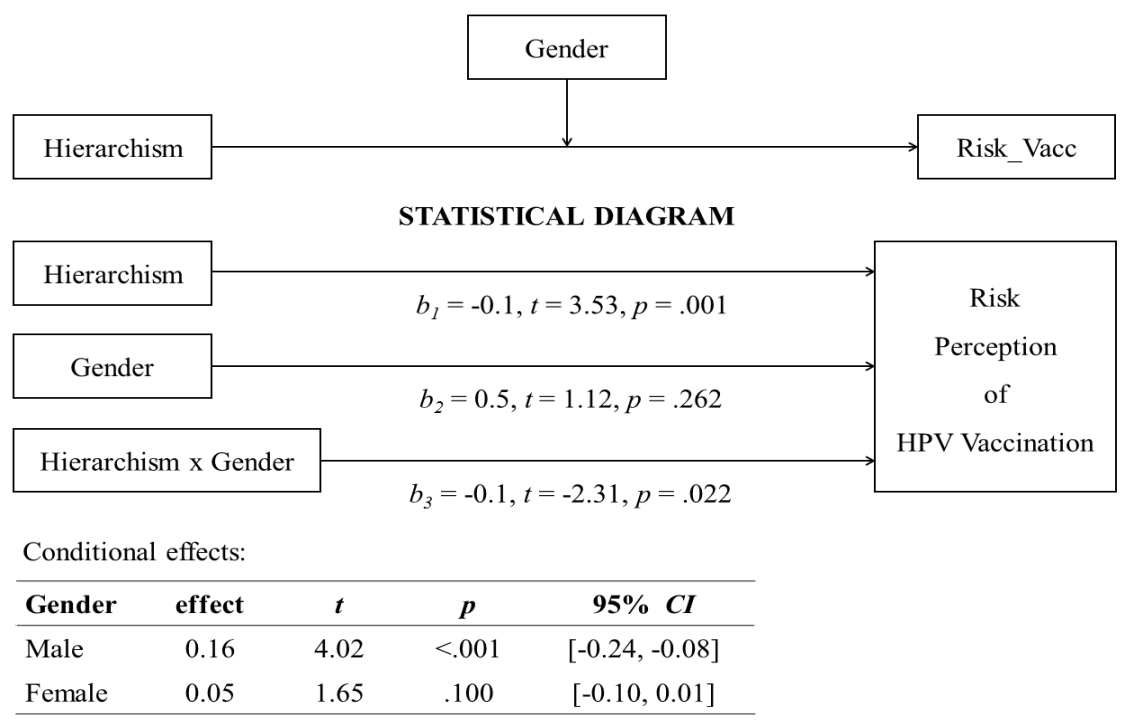

Figure 5 Gender as a moderator of the effect of hierarchism on risk perception of HPV vaccination 
CONCEPTUAL DIAGRAM

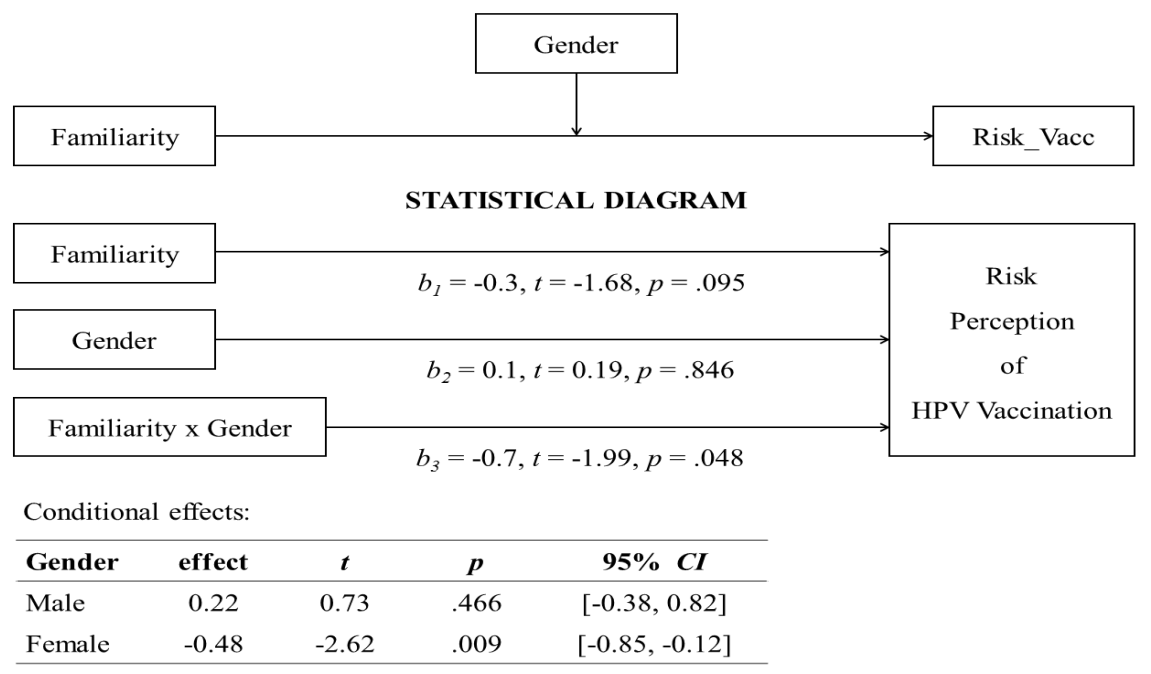

Figure 6 Gender as a moderator of the effect of familiarity on risk perception of HPV vaccination

enables us to compare aspects or risk perception within the two domains.

In the original studies, Kahan et al. (2009, 2010) found different patterns of risk perception based on the two domains: a positive association between risk perception of HPV vaccination and the dimensions of individualism and hierarchism, and a positive relationship between risk perception of nanoscience and the dimensions of communitarianism and egalitarianism. However, we found positive association between hierarchism and risk perception in both domains. We believe that those who prefer hierarchical society are rather conservative and, therefore, might be skeptical and distrustful of scientific and technological progress. Conversely, among more liberal people with an egalitarian worldview, the overall benefits of nanotechnologies for society and its progress probably outweighed potential risks.

Next, we supported the familiarity hypothesis assuming that people are afraid of the things they are not knowledgeable about. Participants who were not exposed to any arguments and were familiar with nanoscience or HPV vaccination, considered them both more beneficial and less risky. Moreover, we identified a general tendency for risk perception across all groups. Those who recognized more risks than benefits of vaccination were likely to do the same for nanotechnology. Since both vaccination and nanoscience are closely related to health domain, the findings support the evidence of predisposition toward risk aversion within a domain (Tversky \& Kahneman, 1992).

According to the first proposed mechanism - confirmation bias - individuals of opposing 
cultural orientation should become more divided when faced with balanced pro- and con-arguments. In the case of nanoscience, balanced arguments amplified evaluated risks, independently of cultural values. We presume that given low level of prior knowledge of nanotechnology in our sample in general, the arguments might have simply made participants aware of previously unknown potential dangers and threats of the novel technology.

Consistently with previous assumption and in line with the credibility heuristic, risk perception of people non-familiar with nanoscience was higher the more their cultural values were similar to those of the con-advocate and the more they differed from those of the pro-advocate. In other words, if a person who had a similar worldview to a participant with low prior nanotechnology knowledge voiced arguments opposing it, the participant was more likely to do so as well - especially if a person with proarguments held completely different cultural values. This result suggests that disagreement about benefits and risks of nanotechnologies is shaped by cultural worldview which exerts its impact via attribution of source credibility. Conversely, people who were well informed about nanoscience prior to our experiment were immune to the effect of proximity of one's own cultural worldview to the worldview of con-advocate versus pro-advocate.

In the domain of HPV vaccination, neither argument exposure nor its interaction with cultural values affected risk perception. In evaluating risks and benefits inherent to vaccination against HPV, gender played a crucial role. First, hierarchism was positively associated with the 'risks $>$ benefits' evaluation only among men. Since the domain is much more personally relevant to women, the presumed association between HPV vaccine and improper, irresponsible sexual behavior probably does not sound acceptable and believable to them. It is reasonable to expect that they feel being fully person- ally responsible for their decisions, and thus do not subscribe to a view that HPV vaccination would make them behave irresponsibly. Among women, the factor positively related to 'benefits > risks' perception was familiarity. Women with very low initial level of information reported higher level of risk perception of vaccination, again probably also because the issue affects them directly and they realized that vaccination can have many facets, including dangerous side-effects and consequences.

In addition, perception of risks and benefits of vaccination against HPV was influenced by cultural worldview of the presumed pro- and con-advocates. The closer the cultural values of the participant to the con-advocate's worldview and the more distant from values of the pro-advocate, the more risks outweighed benefits of HPV vaccination. Along with the results in the nanotechnology domain it seems that when the arguments come from advocates of culturally or otherwise distinctive values that a person can identify with or be opposed to, relevant characteristics of the speaker can play a greater role than the message content.

Despite the demonstrated patterns, future research should overcome some of the methodological limitations of the study reported here. First, greater variability in age, education and prior knowledge in the sample should be ensured. Also, especially for topics that are related to men and women differently (HPV), the sample should aim for a better gender balance. Although the decision to vaccinate their daughter concerns both parents, HPV vaccination is nevertheless more personally relevant to women. It is to be expected that when perceiving higher domain relevance, people will pay more attention to the arguments and will think more carefully about their answers. However, we have included gender in all regression analyses to control for the potential influence of the disproportionate representation of women in our sample. 
We also recommend taking a closer look at participants' self-reported prior familiarity. We adopted the 1-item measure used in prior studies by the Cultural Cognition Project team ("How much did you know about nanotechnology [HPV vaccination] until today?'). It is, however, questionable to what extent the responses represent mere awareness of the issues or actual, relevant knowledge of the potential risks and benefits. Self-reported familiarity can embody not only objective knowledge, but several different aspects such as idiosyncratic subjective knowledge, e.g. misinformation or conspiracy theories about vaccination/nanotechnology. In addition, given the position of the item within the design, we cannot be sure whether the answers had not been affected by the argument exposure for some participants.

Regarding the cultural cognition worldview questionnaire, appropriateness of its use in the context of Central European post-communist society needs to be assessed. We suggest a comparison of the results in CCWS scales and other measures of cultural values. For the purpose of our research, it was crucial that the two dimensions capture a preference for hierarchy (versus solidarity) in the society and for the enforcement of the rights of the individual (versus community). It is possible that Slovak participants attributed slightly different meanings to some of the items than their U.S. counterparts, but this is not in itself problematic, since we did not aim to provide any direct cross-cultural comparisons.

For a more comprehensive analysis, it would be beneficial to collect additional data - e.g. religiosity or political preferences. Association between risk perception, cultural values and cognitive abilities is also worth studying. At the same time, future research could focus on other socially relevant domains that not only represent many potential risks and benefits but are also present within current media and public discourse. Finally, practically-oriented stud- ies might test the effectivity of interventions aimed at neutralizing insufficient or exaggerated risk concerns and impact of cultural cognition mechanisms.

Our research findings corroborate the well documented evidence that conveying scientifically sound objective information is not enough to prevent inadequate risk perception. For example, conflict over vaccination might stem from a failure to empower the target group of the messages (Masaryk \& Hatoková, 2016) and to reflect social factors important in public understanding of science (Kahan, 2013). Identifying factors that underlie risk perception is crucial for cultivating rationality and critical thinking (e.g., Čavojová et al., 2016), finding effective ways of risk communication, and overall debiasing efforts in various domains, such as medicine or finance. Building upon empirical results, we could prepare tutorials for better practice of professionals and enable them to help laymen make adequate informed decisions (e.g., Navarrete, Correia, Sirota, Juanchich, \& Huepe, 2015).

\section{Conclusion}

Human reasoning is full of risk estimates within domains that are complex enough to elicit disagreement even among experts. We see the world through the lens of our values and preferences. And these very attributes underlie our judgments on how serious are certain benefits and risks, how convincing is the evidence and the arguments, and how credible and relevant is a particular source. Cultural cognition may reinforce specific heuristic mechanisms to an undesirable extent and, thus, lead us astray even in situations with high stakes - for us and for others. This paper offers an original explanation of how evaluation of risks and benefits - in the context of novel domains - is affected by a complex interplay of cultural cognition, domain familiarity, personal relevance and general risk attitudes. 


\section{References}

Brewer, N. T., Chapman, G. B., Gibbons, F. X., Gerrard, M., McCaul, K. D., \& Weinstein, N. D. (2007). Metaanalysis of the relationship between risk perception and health behavior: The example of vaccination. Health Psychology, 26, 136-145.

Čavojová, V., Ballová Mikušková, E., Majerník, M., Jurkovič, M., Juhásová, A., \& Masaryk, R. (2016). Rozum: Návod na použitie. Psychológia racionálneho myslenia. Bratislava: IRIS.

Chua, H. F., Ho, S. S., Jasinska, A. J., Polk, T. A., Welsh, R. C., Liberzon, I., \& Strecher, V. J. (2011). Self-related neural response to tailored smoking-cessation messages predicts quitting. Nature Neuroscience, 14, 426-427.

Douglas, M., \& Wildavsky, A. B. (1983). Risk and culture: An essay on the selection of technical and environmental dangers. Berkeley: University of California Press.

Falk, E. B., Berkman, E. T., Mann, T., Harrison, B., \& Lieberman, M. D. (2010). Predicting persuasioninduced behavior change from the brain. The Journal of Neuroscience, 30, 8421-8424.

Field, A. (2009). Discovering statistics using SPSS. London: Sage Publications.

Hagman, W., Andersson, D., Västfjäll, D., \& Tinghög, G. (2015). Public views on policies involving nudges. Review of Philosophy and Psychology, 6, 439-453.

Hayes, A. F. (2013). An introduction to mediation, moderation, and conditional process analysis: $A$ regression-based approach. New York: Guilford Press.

Hilligoss, B., \& Rieh, S. Y. (2008). Developing a unifying framework of credibility assessment: Concept, heuristics, and interaction in context. Information Processing and Management, 44, 1467-1484.

Hornsey, M. J., Harris, E. A., Bain, P. G., \& Fielding, K. S. (2016). Meta-analyses of the determinants and outcomes of belief in climate change. Nature Climate Change, 6, 622-626.

Jenkins-Smith, H. (2001). Modeling stigma: An empirical analysis of nuclear waste images of Nevada. In J. Flynn, P. Slovic, \& H. Kunreuther (Eds.), Risk, media, and stigma: Understanding public challenges to modern science and technology (pp. 107-132). London, Sterling, VA: Earthscan.

Kahan, D. M. (2012). Cultural cognition as a conception of the cultural theory of risk. In S. Roeser, R. Hillerbrand, P. Sandin, \& M. Peterson (Eds.), Handbook of risk theory: Epistemology, decision theory, ethics, and social implications of risk (pp. 725-759). New York: Springer.
Kahan, D. M. (2013). A risky science communication environment for vaccines. Science, 342, 53-54.

Kahan, D. M., Braman, D., Cohen, G. L., Gastil, J., \& Slovic, P. (2010). Who fears the HPV vaccine, who doesn't, and why? An experimental study of the mechanisms of cultural cognition. Law and Human Behavior, 34, 501-516.

Kahan, D. M., Braman, D., Gastil, J., Slovic, P., \& Mertz, C. K. (2007). Culture and identity-protective cognition: Explaining the white male effect in risk perception. Journal of Empirical Legal Studies, 4, 465-505.

Kahan, D. M., Braman, D., Slovic, P., Gastil, J., \& Cohen, G. L. (2009). Cultural cognition of the risks and benefits of nanotechnology. Nature Nanotechnology, 4, 87-90.

Kumkale, G. T., Albarracín, D., \& Seignourel, P. J. (2010). The effects of source credibility in the presence or absence of prior attitudes: Implications for the design of persuasive communication campaigns. Journal of Applied Social Psychology, 40, 13251356.

Leiserowitz, A. A. (2005). American risk perceptions: Is climate change dangerous? Risk Analysis, 25, 14331442.

Masaryk, R., \& Hatoková, M. (2016). Qualitative inquiry into reasons why vaccination messages fail. Journal of Health Psychology. Advance online publication.

Navarrete, G., Correia, R., Sirota, M., Juanchich, M., \& Huepe, D. (2015). Doctor, what does my positive test mean? From Bayesian textbook tasks to personalized risk communication. Frontiers in Psychology, 6, 1327.

Nesler, M. S., Aguinis, H., Quigley, B. M., \& Tedeschi, J. T. (1993). The effect of credibility on perceived power. Journal of Applied Social Psychology, 23, 1407-1425.

Nickerson, R. S. (1998). Confirmation bias: A ubiquitous phenomenon in many guises. Review of General Psychology, 2, 175-220.

Renner, B., \& Reuter, T. (2012). Predicting vaccination using numerical and affective risk perceptions: the case of A/H1N1 influenza. Vaccine, 30, 70197026.

Shi, J., Visschers, V. H. M., \& Siegrist, M. (2015). Public perception of climate change: The importance of knowledge and cultural worldviews. Risk Analysis, 35, 2183-2201.

Sunstein, C. R. (2002). Risk and reason. Safety, law, and the environment. Cambridge, UK: Cambridge University Press.

Stanovich, K. E., West, R. F., \& Toplak, M. E. (2013). Myside bias, rational thinking, and intelligence. Psychological Science, 22, 259-264. 
Tversky, A., \& Kahneman, D. (1974). Judgment under uncertainty - heuristics and biases. Science, 185 , 1124-1131.
Tversky, A., \& Kahneman, D. (1992). Advances in prospect theory: Cumulative representation of uncertainty. Journal of Risk and Uncertainty, 5, 297323 . 